\title{
PENGAMBILAN KEPUTUSAN DALAM PELAKSANAAN RUJUKAN KE RUMAH SAKIT
}

\author{
Ananda Muthia Bahri Hasibuan \\ anandamuthiag3@gmail.com
}

\section{LATAR BELAKANG}

Pelayanan kesehatan dilaksanakan secara berjenjang dimulai dari pelayanan kesehatan tingkat pertama. Pelayanan kesehatan tingkat kedua hanya dapat diberikan atas rujukan dari pelayanan kesehatan tingkat pertama. Pelayanan kesehatan tingkat ketiga hanya dapat diberikan atas rujukan dari pelayanan kesehatan tingkat kedua atau tingkat pertama, kecuali pada kadaan gawat darurat, kekhususan permasalahan kesehatan pasien, pertimbangan geografis, dan pertimbangan ketersediaan fasilitas. Sistem rujukan diselenggarakan dengan tujuan memberikan pelayanan kesehatan secara bermutu, sehingga tujuan pelayanan tercapai tanpa harus menggunakan biaya yang mahal.

Kesehatan merupakan salah satu aspek yang terpenting dalam kehidupan manusia. Setiap orang akan berusaha untuk mempertahankan derajat kesehatannya. Salah satu upaaya untuk mempertahankan derajat kesehatan tersebut adalah dengan cara menggunakan layanan kesehatan yang disedakan oleh pemerintah maupun swasta. Pemerintah maupun swasta telah menyediakan beberapa layanan kesehatan yang bersifat bangunan fisik untuk masyarakat seperti rumah sakit, puskesmas, panti jompo, dan layanan kesehatan.

Jaminan Kesehatan Nasional (JKN) merupakan implementasi dari UU Nomor 40 Tahun 2004 tentang Sistem Jaminan Sosial Nasional (SJSN) di bidang kesehatan dengan konsep Universal Health Coverage (UHC) yang memaksa pesertanya mengikuti sistem rujukan untuk mendapatkan pelayanan kesehatan komprehensif, murah, terjangkau, namun berkualitas. Diberlakukannya SJSN ini jelas menuntut dilakukannya peningkatan akses dan mutu pelayanan kesehatan, baik pada fasilitas kesehatan tingkat pertama maupun fasilitas kesehatan tingkat lanjutan, serta perbaikan sistem rujukan pelayanan kesehatan.Pelayanan yang proaktif itu adalah "Sistem Rujukan Nasional".

Pada Pasal 5PMK No. 001Tahun2012, dinyatakan bahwa sistem rujukan diwajibkan bagi peserta jaminan kesehatan atau asuransi kesehatan sosial dan juga pemberi pelayanan kesehatan. Dengan Sistim Rujukan Nasional ini dapat mengenal kelompok Golongan Risiko 
Tinggi yang memerlukan penanganan khusus yang tidak terdapat di layanan kesehatan primer seperti Puskesmas. Rujukan pelayanan kesehatan dimulai dari pelayanan kesehatan primer dan diteruskan ke jenjang pelayanan sekunder dan tersier yang hanya dapat diberikan jika ada rujukan dari pelayanan primer atau sekunder,minimal di Rumah Sakit Kota.

Sistem rujukan diselenggarakan dengan tujuan memberikan pelayanan kesehatan secara bermutu, sehingga tujuan pelayanan tercapai tanpa harus menggunakan biaya yang mahal. Hal ini disebut efektif sekaligus efisien. Efisien juga diartikan dengan berkurangnya waktu tunggu dalam proses merujukdan berkurangnya rujukan yang tidak perlu karena sebenarnya dapat ditangani di fasilitas pelayanan kesehatan asal, baik dengan bantuan teknologi mutakhir ataupun teknologi tepat guna atau low cost technology, yang tetap masih dapat di pertanggung-jawabkan (Anonim, 2012). Saat ini, kasus rujukan ke layanan sekunder untuk kasus-kasus yang seharusnya dapat dituntaskan di layanan primer masih cukup tinggi. Berbagai faktor mempengaruhi diantaranya kompetensi dokter, pembiayaan, dan sarana prasarana yang belum mendukung.

Sebagian besar penyakit dengan kasus terbanyak di Indonesia berdasarkan Riset Kesehatan Dasar (Riskesdas) 2007 dan 2010 termasuk dalam kriteria 4a (dokter mampu mendiagnosa penyakit dengan baik dan mampu melakukan penatalaksanaan secara baik dan benar) dengan menekankan pada tingkat kemampuan 4 (dokter mempunyai kemampuan untuk menyelesaikan 144 diagnosa penyakit di puskesmas). Bila pada pasien telah terjadi komplikasi, tingkat keparahan (severity of illness), adanya penyakit kronis lain yang sulit dan pasien dengan daya tahan tubuh menurun, yang seluruhnya membutuhkan penanganan lebih lanjut, maka dokter layanan primer secara cepat dan tepat harus membuat pertimbangan dan memutuskan dilakukannya rujukan (Anonim, 2014b).

Menurut Taher (2013), masih ada masyarakat yang belum tahu teknis mendapatkan pelayanan sesuai dengan aturan BPJS Kesehatan. Masyarakat yang akan berobat ke rumah sakit umum pemerintah dengan kartu BPJS harus mendapat rujukan dari dokter, klinik/puskesmas, atau rumah sakit umum daerah. Masyarakat yang datang ke rumah sakit sekunder, akan dilayani jika sudah mendapatkan rujukan dari pelayanan kesehatan primer, sesuai dengan Peraturan Menteri Kesehatan No. 001/2012 Tentang Sistem Rujukan Pelayanan Kesehatan Perorangan. Aturan ini diterbitkan agar Program Jaminan Kesehatan Nasional (JKN) dapat berjalan baik. 


\section{METODE}

Melakukan obeservasi yang didasarkan atas literatur penelitian. Dijelaskan secara deskriptif. Berdasarkan literatur tersebut akan disesuaikan dengan judul jurnal ini pengambilan keputusan dalam pelaksanaan rujukan ke rumah sakit. Metode yang saya gunakan yaitu dengan menggunakan metode literatur review dengan pendekatan jurnal, tesis, buku dan ebook untuk mendapatkan data yang akurat mengenai perencanaan keperawatan dalam keluarga. Adapun jurnal atau artikel dan e-book yang digunakan pada literatur review adalah jurnal dan e-book yang didapatkan dengan menggunakan google scholar .

\section{HASIL}

Pelaksanaan rujukan yang terjadi di lapangan berbeda bahwa beberapa rujukan terjadi atas permintaan pasien, pasienpun menentukan dalam pemberian rujukan (Ali, et al., 2015). Rujukan vertikal dari tingkatan pelayanan yang lebih tingi ke tingkatan pelayanan yang lebih rendah dapat dilakukan apabila permasalahan kesehatan pasien dapat ditangani oleh tingkatan pelayanan kesehatan yang lebih rendah sesuai dengan kompetensi dan kewenangannya, kompetensi dan kewenangan pelayanan tingkat pertama atau kedua lebih baik dalam menangani pasien tersebut, pasien membutuhkan pelayanan lanjutan yang dapat ditangani oleh tingkatan pelayanan kesehatan yang lebih rendah dan untuk alasan kemudahan, efisiensi dan pelayanan jangka panjang dan/atau perujuk tidak dapat memberikan pelayanan kesehatan sesuai dengan kebutuhan pasien karena keterbatasan sarana, prasarana, peralatan dan/atau ketenagaan (Pasal 10) (Kemenkes RI, 2012).

Rujukan harus mendapatkan persetujuan dari pasien dan atau keluarganya, serta tenaga kesehatan yang berwenang harus memberikan penjelasan kepada pasien mengenai diagnosis dan terapi atau tindakan medis yang diperlukan oleh pasien, alasan dan tujuan dilakukan rujukan, risiko yang dapat timbul apabila rujukan tidak dilakukan, transportasi rujukan, dan risiko atau penyulit yang dapat timbul selama perjalanan (Pasal 12) (Kemenkes RI, 2012)

Prosedur rujukan diawali dari masyarakat yang membutuhkan pelayanan kesehatan dan harus dilakukan oleh tenaga kesehatan. Jika rumahsakit tidak memiliki kemampuan dan kewenangan serta pasien membutuhkan pelayanan kesehatan lanjutan, rumah sakit wajib merujuk. Prosedur rujukan yang dilakukan oleh rumah sakit harus memenuhi standar 
prosedur meliputi: merujuk, menerima rujukan, membalas rujukan, menerima balasan rujukan, pengelolaan pasien di ambulans, dan rujukan kasus khusus. Kelengkapan sarana dan prasarana di rumah sakit juga akan mempengaruhi dokter dalam memberikan rujukan kepada pasien.

Tata laksana rujukan dari fasilitas pelayanan kesehatan tingkat pertama ke tingkat kedua terdiri dari syarat merujuk pasien dan prosedur standar merujuk pasien yaitu prosedur klinis dan administratif rujukan (Kemenkes RI, 2012).

Syarat untuk merujuk pasien dalam Kemenkes RI (2012), yaitu:

1. Hasil pemeriksaan sudah dapat dipastikan tidak mampu diatasi secara tuntas di fasyankes

2. Hasil pemeriksaan fisik dengan pemeriksaan penunjang medis ternyata pasien tidak mampu diatasi secara tunts ataupun tidak mampu dilayani karena keterbatasan sarana/prasarana

3. Pasien memerlukan pemeriksaan penunjang medis yang lebih lengkap dan pemeriksaan harus disertai pasien yang bersangkutan.

4. Apabila pasien telah diobati di rumah sakit ternyata masih membutuhkan pemeriksaan, pengobatan dan atau perawat di rumah sakit rujukan yang lebih mampu untuk dapat menyelesaikan masalah kesehatan.

\section{PEMBAHASAN}

Pengambilan keputusan adalah proses memilih suatu pemecahan masalah dari beberapa alternatifyang tersedia (Williams, 2001:189). Pengambilan keputusan melukiskan proses pemilihan suatu arahtindakan sebagai cara untuk memcahkansebuahmasalah tertentu (Stoner, 2003:204).Pengambilan keputusan dapat diartikan sebagai rangkaian kegiatan penataan untuk melakukan pemilihan di antara berbagai kemungkinan untuk menyelesaikan persoalan, pertentangan, kebimbangan yang timbul dalam kerjasama sekelompok orang untuk mencapai tujuan tertentu(Sutarto, 2002:329).

Proses dasar pembuatan keputusan hampir sama dengan proses perencanaan strategik. Ini mencakup identifikasi dan diagnosamasalah, pengumpulan dan analisa data yang relevan, pengembangan alternatif -alternatif, penilaian berbagai alternatif penyelesaian, pemilihan 
alternatif terbaik, implementasi keputusan dan evaluasi terhadap hasil-hasil(Handoko, 2001:134). Proses pengambilan keputusan yang diajukan antara lain:

1. Tahap 1: Identifikasi masalah

Langkah pertama dalam pengambilan keputusan adalah mengenali (mengidentifikasi) dan menentukan (mendefinisikan) masalah (Williams, 2001:132). Proses pemecahan masalah dimulai bila masalah telah ditemukan untuk diambil tindakan.

2. Tahap II: Pengumpulan data yang relevan

Setelah manajer menentukan dan merumuskan masalah, mereka harus mulai menentukan langkah-langkah selanjutnya. Manajer pertama kali harus menentukan data-data apa yang akan dibutuhkan untuk membuat keputusan yang tepat dan kemudian mendapatkan informasi tersebut (Handoko, 2001:134).

3. Tahap III: Pengembangan alternatif

Sebelum suatu keputusan dibuat, alternatif yang masuk akal (solusi potensial untuk masalah tersebut) mesti telah ditelaah serta akibat dari masing-masing altenatif juga mesti dikaji. Mengembangkan alternatif adalah suatu proses pencarian dengan meneliti lingkungan internal dan eksternal organisasi guna memperoleh informasi sehingga dapat dikembangkan menjadi alternatif yang mungkin. Upaya pencarian untuk mengembangkan alternatif ini dibatasi oleh waktu dan biaya (Gibson,1997).

4. Tahap IV: Evaluasi alternatif

Setelah manajer mengembangkan sekumpulan alternatif, mereka harus mengevaluasinya untuk menilai efektivitas setiap alternatif. Tujuan pengambilan keputusan adalah memilih alternatif yang memungkinkan untuk memperoleh hasil yang paling menguntungkan sedikit mungkin yang tidak menguntungkan (Handoko, 2001:135).

5. Tahap V: Memilih alternatif

Tahap kelima pengambilan keputusan merupakan hasil evaluasi berbagai alternatif. Maksud memilih alternatif adalah untuk memecahkan masalah guna mencapai tujuan yang direncanakan sebelumnya. Tahap kelima pengambilan keputusan merupakan hasil evaluasi berbagai alternatif. Maksud memilih alternatif adalah untuk memecahkan masalah guna mencapai tujuan yang direncanakan sebelumnya. Alternatif terpilih akan didasarkan pada jumlah informasi yang tersedia bagi manajer dan ketidaksempurnaan kebijakan manajer. Pilihan alternatif terbaik 
juga sering merupakan suatu kompromi diantara berbagai faktor yang telah dipertimbangkan (Handoko, 2001:136).

6. Tahap VI: Implementasi Keputusan

Sangat mungkin terjadi keputusan yang bagus menjadi hancur karena implementasi yang buruk. Dalam beberapa hal, implementasi menjadi lebih penting dari sekedar memilih alternatif. Implementasi keputusan melibatkan banyak orang sehingga untuk menguji keputusan itu dapat dengan melihat perilaku orang yang dipengaruhi keputusan itu. Suatu keputusan yang secara teknis bagus dapat saja hancur karena bawahan yang tidak puas. Jadi tugas manajer tidak hanya memilih solusi yang tepat tetapi juga menterjemahkan solusi menjadi pola perilaku organisasi (Gibson, 1997).

Rujukan adalah pelimpahan wewenang dan tanggung jawab atas kasus penyakit atau masalah kesehatan yang diselenggarakan secara timbal balik, baik secara vertikal dalam arti satu strata sarana pelayanan kesehatan ke strata sarana pelayanan kesehatan lainnya, maupun secara horisontal dalam arti antar sarana pelayanan kesehatan yang sama (Kemenkes no 128, 2004:14).

Sistem Rujukan Sistem rujukan di Indonesia dibedakan atas 2 jenis yaitu rujukan medis dan rujukan kesehatan. Rujukan medis adalah upaya rujukan kesehatan yang dapat $\mathrm{m}$ bersifat vertikal, horizontal atau timbal balik yang terutama berkaitan dengan upaya penyembuhan dan rehabilitasi serta upaya yang bertujuan mendukungnya. Rujukan kesehatan adalah rujukan upaya kesehatan yang bersifat vertikal danhorisontal yang terutama berkaitan dengan upaya peningkatan dan pencegahan serta upaya yang mendukungnya (Dinkes Jakarta, 2014:3).

Pasien yang akan dirujuk harus sudah diperiksa dan layak untuk dirujuk. Adapun kriteria pasien yang dirujuk adalah bila memenuhi salah satu dari:

a. Hasil pemeriksaan fisik sudah dapat dipastikan tidak mampu diatasi

b. Hasil pemeriksaan fisik dengan pemeriksaan penunjang medis ternyata tidak mampu diatasi dan apabila telah diobati dan dirawat ternyata memerlukan pemeriksaan, pengobatan dan perawatan di fasilitas pelayanan kesehatan yang lebih mampu

c. Memerlukan pemeriksaan penunjang medis yang lebih lengkap, tetapi pemeriksaan harus disertai pasien yang bersangkutan.

d. Mencantumkan terapi sementara 
e. Mencantumkan tindakan yang telah diberikan

f. Mencantumkan alasan merujuk

g. Mencantumkan tanda tangan dokter yang merujuk

h. Pasien di dampingi tenaga kesehatan saat merujuk kecuali untuk rujukan rawat jalan.

i. Menggunakan ambulance transport kecuali untuk rujukan rawat jalan

j. Memberikan edukasi pada pasien tentang proses rujukan

k. Komunikasi dengan RS yang akan menjadi tujuan rujukan sebelum mengirim pasien kecuali untuk rujukan rawat jalan dan kasus gawat darurat KIA

1. Pasien dirujuk $1 \times 24 j a m$ sejak diagnosa ditegakkan kecuali untuk rujukan rawat jalan.

Rujukan harus mendapatkan persetujuan dari pasien dan atau keluarganya, serta tenaga kesehatan yang berwenang harus memberikan penjelasan kepada pasien mengenai diagnosis dan terapi atau tindakan medis yang diperlukan oleh pasien, alasan dan tujuan dilakukan rujukan, risiko yang dapat timbul apabila rujukan tidak dilakukan, transportasi rujukan, dan risiko atau penyulit yang dapat timbul selama perjalanan (Pasal 12) (Kemenkes RI, 2012).

Surat pengantar rujukan pasien sekurang- kurangnya harus memuat mengenai identitas pasien, hasil pemeriksaan (anamnesis, pemeriksaan fisik dan pemeriksaan penunjang) yang telah dilakukan, diagnosis kerja, terapi/tindakan yang telah diberikan, tujuan rujukan, nama dan tanda tangan tenaga kesehatan yang memberikan pelayanan (Pasal 15) (Kemenkes RI, 2012).

\section{PENUTUP}

Pengambilan keputusan adalah proses memilih suatu pemecahan masalah dari beberapa alternatifyang tersedia (Williams, 2001:189). Pengambilan keputusan melukiskan proses pemilihan suatu arahtindakan sebagai cara untuk memcahkansebuahmasalah tertentu (Stoner, 2003:204).Pengambilan keputusan dapat diartikan sebagai rangkaian kegiatan penataan untuk melakukan pemilihan di antara berbagai kemungkinan untuk menyelesaikan persoalan, pertentangan, kebimbangan yang timbul dalam kerjasama sekelompok orang untuk mencapai tujuan tertentu(Sutarto, 2002:329).

Proses pengambilan keputusan yang diajukan antara lain: 
1. Tahap 1: Identifikasi masalah

2. Tahap II: Pengumpulan data yang relevan

3. Tahap III: Pengembangan alternatif

4. Tahap IV: Evaluasi alternatif

5. Tahap V: Memilih alternatif

6. Tahap VI: Implementasi Keputusan

Rujukan adalah pelimpahan wewenang dan tanggung jawab atas kasus penyakit atau masalah kesehatan yang diselenggarakan secara timbal balik, baik secara vertikal dalam arti satu strata sarana pelayanan kesehatan ke strata sarana pelayanan kesehatan lainnya, maupun secara horisontal dalam arti antar sarana pelayanan kesehatan yang sama (Kemenkes no 128, 2004:14).

Syarat untuk merujuk pasien dalam Kemenkes RI (2012), yaitu:

1. Hasil pemeriksaan sudah dapat dipastikan tidak mampu diatasi secara tuntas di fasyankes

2. Hasil pemeriksaan fisik dengan pemeriksaan penunjang medis ternyata pasien tidak mampu diatasi secara tunts ataupun tidak mampu dilayani karena keterbatasan sarana/prasarana

3. Pasien memerlukan pemeriksaan penunjang medis yang lebih lengkap dan pemeriksaan harus disertai pasien yang bersangkutan.

4. Apabila pasien telah diobati di rumah sakit ternyata masih membutuhkan pemeriksaan, pengobatan dan atau perawat di rumah sakit rujukan yang lebih mampu untuk dapat menyelesaikan masalah kesehatan.

\section{DAFTAR PUSTAKA}

Ali, F, A,. (2015). Analisis Pelaksanaan Rujukan Rawat Jalan Tingkat Pertama Peserta Program Jaminan Kesehatan Nasional (JKN) Di Puskesmas Siko Dan Puskesmas Kalumata Kota Ternate Tahun 2014. JIKMU, Vol. 5, No. 2, April 2015.

Mustainah. (2017). "IMPLEMENTASI SISTEM RUJUKAN JKN DI RUMAH SAKIT STELLA MARIS”. Fakultas Kesehatan Masyarakat.Makassar: Universitas Hasanuddin. 
Nurlinawati, I,. (2019). GAMBARAN FAKTOR PENYEBAB RUJUKAN DI PUSKESMAS KOTA DEPOK. Buletin Penelitian Sistem Kesehatan - Vol. 22 No. 3 176-183.

Nusawakan, A, A,. (2017). FAKTOR YANG MEMPENGARUHI PENGAMBILAN KEPUTUSAN DALAM PENGGUNAAN LAYANAN KESEHATAN PADA WILAYAH KERJA PUSKESMAS TAWIR. Media Ilmu Kesehatan Vol. 6, No. 2

Purwati, E, I, I,. (2017). Pengambilan Keputusan dalam Pelaksanaan Rujukan Puskesmas sebagai Fasilitas Kesehatan Tingkat Pertama. e-Jurnal Pustaka Kesehatan, Vol. 5, (No. 2).

Ratnasari, D,. (2017). Analisis Pelaksanaan Sistem Rujukan Berjenjang Bagi Peserta JKN di Puskesmas X Kota Surabaya. JAKI Volume 5 Nomor 2.

Simamora, R. H. (2019). Menjadi perawat yang: CIH'HUY. Surakarta: Kekata Publisher.

Simamora, R. H. (2005). Hubungan Persepsi Perawat Pelaksana Terhadap Penerapan Fungsi Pengorganisasian Yang Dilakukan Oleh Kepala Ruangan Dengan Kinerjanya Diruang Rawat Inap RSUD Koja Jakarta Utara (Doctoral dissertation, Tesis FIK UI, Tidak dipublikasikan).

Sumarnia, Anasari, T., (2014). FAKTOR YANG MEMPENGARUHI KETERLAMBATAN RUJUKAN PADA KASUS KEMATIAN IBU DI RS MARGONO SOEKARDJO. Jurnal Ilmiah Kebidanan, Vol. 5 No. 2 Edisi Desember 2014, hlm. 26-34.

Wandi. (2017). IMPLEMENTASI SISTEM RUJUKAN IBU HAMIL DAN BERSALIN OLEH BIDAN POLINDES. JURNAL INFORMASI KESEHATAN INDONESIA, VOLUME 3, NO. 1, 71-84.

Widyaningrum, L., Tamtomo, D., dkk. (2016). Evaluation on the Implementation of Regional Mapping Referal System in the National Health Insurance Primary Care Services in Boyolali, Central Jawa. Journal of Health Policy and Management 1(2): 95-101.

Wulandari, A, P, Susanti, A, I, dkk. (2016). Gambaran Pengambilan Keputusan Saat Proses Rujukan dari Tingkat Primer ke Tingkat Sekunder di Rumah Sakit Umum Daerah Sumedang. JSK, Volume 2 Nomor 2. 